\title{
A HYBRID DESIGN PROCEDURE FOR FAULT DIAGNOSIS IN A PV POWER PLANT
}

\author{
Fawzi M. Al-Naima
}

Al-Mamoon University College, Dept. of Computer Eng., Baghdad, Iraq

\section{Maysam M. Wahab}

Al-Nahrain University, Dept. of Computer Eng., Baghdad, Iraq

CMESTE

JEL Category: L86, 013, Q42

\begin{abstract}
A solar panel monitoring system is an indispensable part and should be of priority in the design of solar power plants to get the highest possible efficiency of solar panels. This paper presents a hybrid PV solar plant monitoring system based on two communication technologies; namely WSN and RFID. The first part consists of multi-sensors (voltage, current, temperature, humidity, dust, smoke, irradiation, and rain) installed on each PV panel. These sensors will collect data from the panels and send them to a cloud database via Wi-Fi modules. The user can log in to this cloud database and display the recorded data in real-time. The second part utilizes RFID as a supporter when the internet is not available. A microcontroller will send data to the local control room in the solar station via Radio Frequency (RF) modules. A panel information detector will be added to this monitoring system to facilitate detect PV panel's history information. In addition, the fault detector software is based on the C\# programming language and MySQL database. Some practical verifications of the proposed monitoring system have been successfully obtained from an experimental set-up installed on the existing solar station installed on the rooftop of the building of the Technical Institute in the city of Baquba, Iraq.
\end{abstract}

Keywords: WSN, RFID, solar energy, monitoring system, hybrid system, fault detection, wi-fi module, $P V$ system, cloud server, RF module

\section{INTRODUCTION}

Solar power has become one of the most important sources of electricity generation in modern times where it has become a destination for developed countries to provide the electricity

Address of the corresponding author:

Fawzi Al-Naima

䒠=f fawzi.alnaima@ieee.org needed to meet their needs as it is considered successful alternative energy for fossil fuel. Despite the existing high cost of building solar power plants, they are a clean and environmentally friendly source where it does not generate noise and does not cause air pollution, as it converts the solar energy into direct electric power by the photovoltaic effect.

However, one of the main reasons that might not make this technology be more popular to be in the 
top spot is that it is often exposed to faults and malfunctions leading to many external unwanted effects. These faults lead to a decrease in efficiency and a lack of power to meet the need for them compared to the cost of their construction (Al-Naima \& Hamad, 2019). A number of failure modes of PV modules are observed in the field during operation and in the laboratory during testing for certification. Climate chamber tests, hot spot tests, and mechanical load tests have been identified as the most severe tests in the current standards (Ferrara \& Philipp, 2012). A wireless sensor network for the monitoring of large PV plants has been proposed in recent research papers with an approach that relies on network sensors that collect detailed information about the electrical performance of each series of the photovoltaic plant. Performance analysis logic has been developed and implemented in a software control tool that analyses aggregated data and generates graphical reports to determine the immediate location of failures and yield losses (Guerriero et al., 2014) (Wahyuni \& Wijaya, 2017).

In order to reduce the impact of these factors on energy production, it is imperative to design a solar panel monitoring system to monitor the energy production of individual solar panels. As well as external factors that reduce its energy production moment by moment and detect any fault that occurs in any solar panel and know the type of error and the causative factor (Bashir, Lim, Hussain, \& Park, 2011) (Jaiswal, 2015). To facilitate the detection and maintenance of the damaged board as soon as possible, in this paper a hybrid monitoring system is designed and implemented based on two modern communications technologies, namely the RFID and the WSN in order to get a highly reliable system.

\section{THE PROPOSED HYBRID SYSTEM}

The PV panels under test installed on the rooftop of the building of the Technical Institute in the city of Baquba, Iraq. They are Mono Crystalline Solar PV Module Fortune FRS 250W for Domestic/ commercial applications, with a maximum power of $250 \mathrm{~W}$ as shown in Figure 1. This station consists of 60 such panels with technical specifications shown in Table 1. A monitoring circuit is allocated to each panel as transmitter and receiver parts. These parts consist of hardware and software to program these hardware components. The data collected from the sensors are sent to the local server PC via NRF24 to detect faults in the panels. The Nordic nRF24 is a family of silicon integrated radio transceivers operating in the $2.4 \mathrm{GHz}$ band.

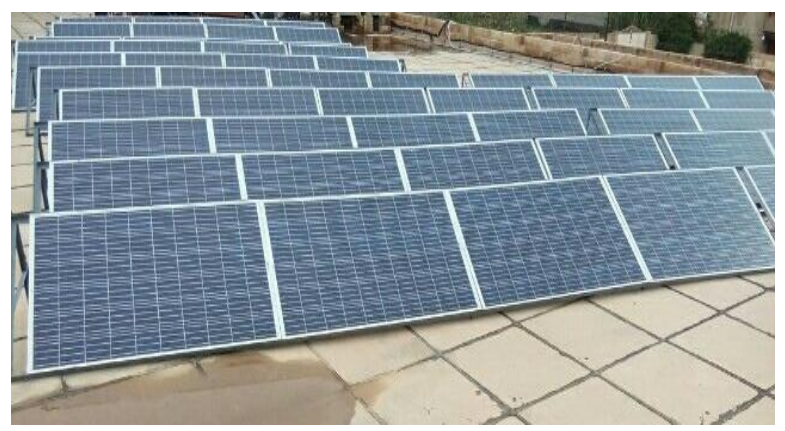

Fig. 1 The Solar Panels Under Test

Table 1. Solar panel specifications

\begin{tabular}{|l|l|}
\hline Module Type & FRS-250W \\
\hline Peak power $\left(\mathrm{P}_{\max }\right)$ & $250.00 \mathrm{~W}$ (peak) \\
\hline Peak voltage $\left(\mathrm{V}_{\mathrm{mp}}\right)$ & $30.50 \mathrm{~V}$ \\
\hline Peak current $\left(\mathrm{I}_{\mathrm{mp}}\right)$ & $8.20 \mathrm{~A}$ \\
\hline Short circuit current $\left(\mathrm{I}_{\mathrm{sc}}\right)$ & $8.72 \mathrm{~A}$ \\
\hline Open circuit voltage $\left(\mathrm{V}_{\mathrm{oc}}\right)$ & $37.20 \mathrm{~V}$ \\
\hline
\end{tabular}

\subsection{Transmitter Side}

In order to design a fault detection system for a solar station, many hardware components are needed. There are various types of components that can be used in the detection system, but the cost should be considered. In this project, the components used are simple and of low cost. An ACS712 Current Sensor is used to measure the DC current, Arduino 25V Voltage Sensor Module is used to measure DC voltage of the panel. The temperature and humidity are determined by a DHT11 Temperature and Humidity Sensor. The DSM501A dust sensor module is used to measure the percentage of dust on the panel. MQ4 Methane Gas Sensor is used to detect fire or damage that may occur in the panels. Rain Sensors Module FC-37 is used to detect if it is raining. All these sensors are connected to the Arduino Mega as a microcontroller that reads the sensor data and sends them to the cloud database via the ESP8266 Wi-Fi module or to air via NRF24L0 module, which can be detected by a receiver in the local control room. NRF24L0 module is used for sending and receiving data at 
an operating radio frequency of 2.4 to $2.5 \mathrm{GHz}$ ISM band (Bilic, Buyukoztekin, \& Ozdemir, 2019). Figure 2 shows a flowchart for the transmitter side. The transmitter side system design is shown in Figure 3.

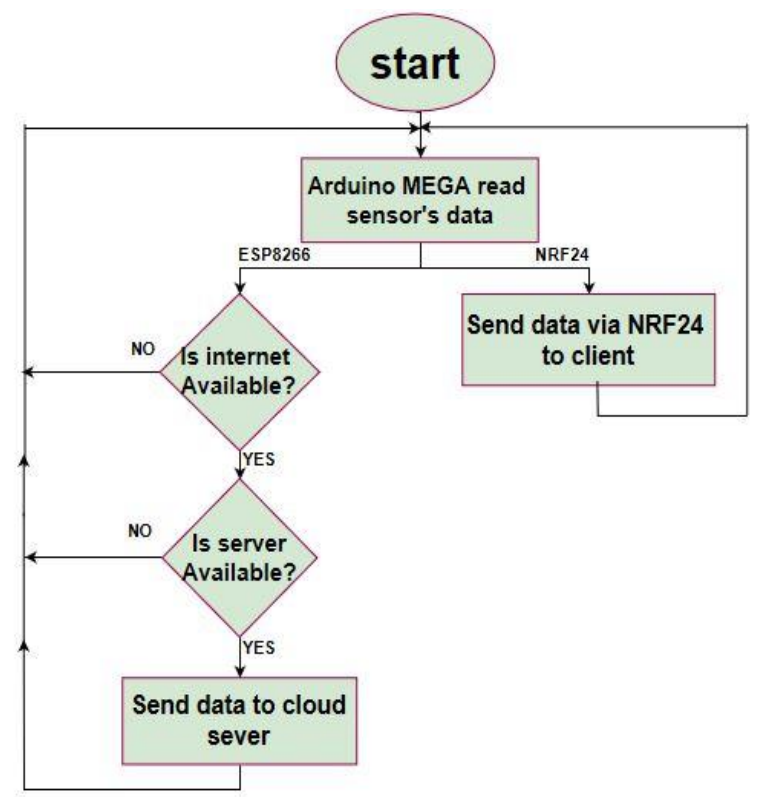

Fig. 2 Flowchart of WSN system transmitter side

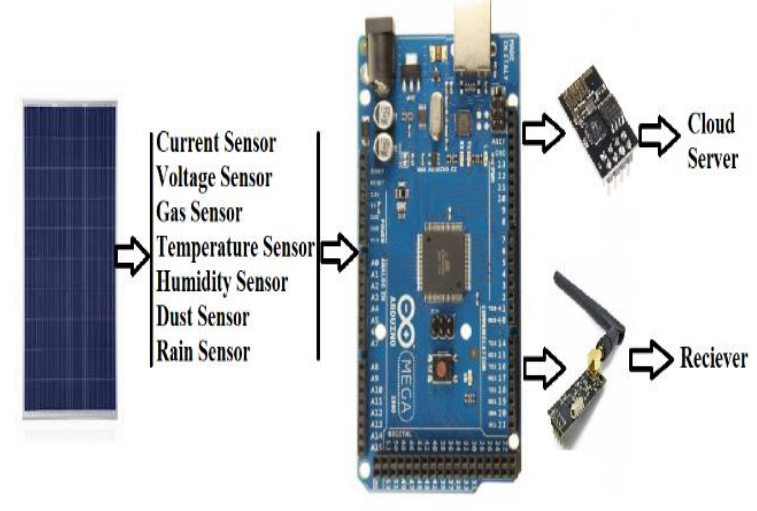

Fig. 3 Transmitter side system design

\subsection{Receiver Side}

Figure 4 shows a flowchart of the local receiver side, while Figure 5 shows the local receiver side system design. The Receiver can detect the available radio signal in the air and received it, then store it in the MySQL database to be displayed with GUI software designed by $\mathrm{C \#}$ programming language to display received data and detect the fault types and their causes. This part of the receiver side is very useful when the internet is not available in the solar station, which guarantees to store all data when the internet is not available. In addition, if the internet is available, Mega will send sensors data to a cloud database via ESP8266 that anyone can log in and display remotely. A Real-time clock RTC DS3231 is added to display the time of each recorded process.

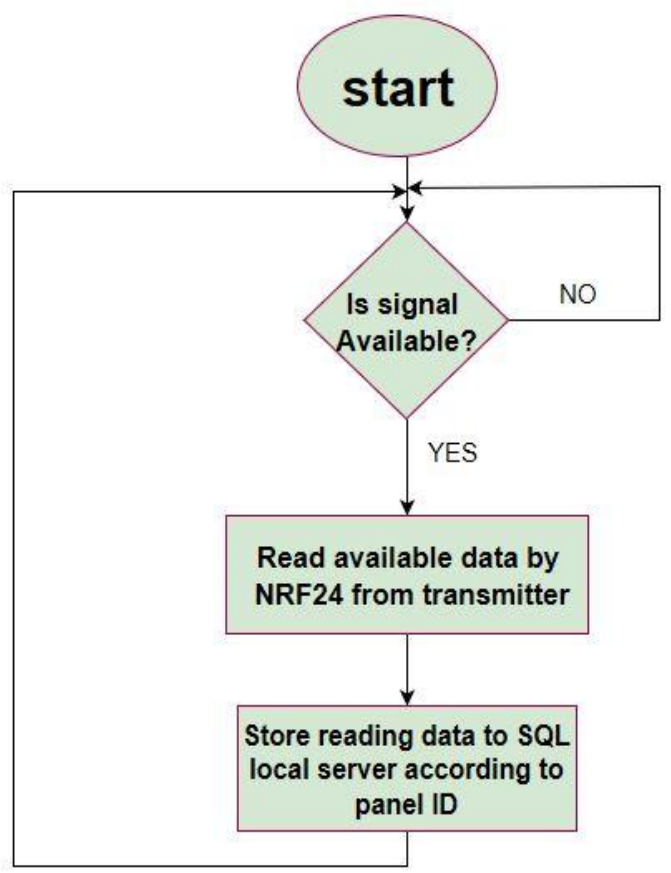

Fig. 4 Flowchart of the local receiver

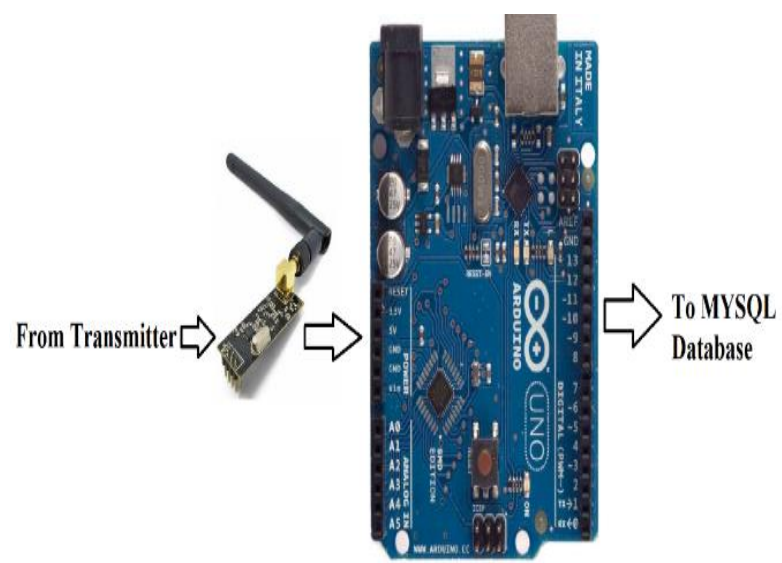

Fig. 5 Local receiver system design

\section{FAULT DETECTOR SOFTWARE}

The software is designed to detect the faults and their causes to facilitate maintenance of the panels by using $\mathrm{C \#}$ programming language and MySQL database to store recorded data and display them by the designed software as portrayed in Figure 6, Figure7 and Figure 8 respectively. 


\begin{tabular}{|l|l|l|l|l|l|l|l|l|l|}
\hline 1 & \multicolumn{1}{c|}{ Solar Fault Detection } \\
\hline 1 & 3 & 4 & 5 & 6 & 7 & 8 & 9 & 10 \\
\hline 11 & 12 & 13 & 14 & 15 & 16 & 17 & 18 & 19 & 20 \\
\hline 21 & 22 & 23 & 24 & 25 & 26 & 27 & 28 & 29 & 30 \\
\hline 31 & 32 & 33 & 34 & 35 & 36 & 37 & 38 & 39 & 40 \\
\hline 41 & 42 & 43 & 44 & 45 & 46 & 47 & 48 & 49 & 50 \\
\hline 51 & 52 & 53 & 54 & 55 & 56 & 57 & 58 & 59 & 60 \\
\hline
\end{tabular}

Fig. 6 Fault detector software home page

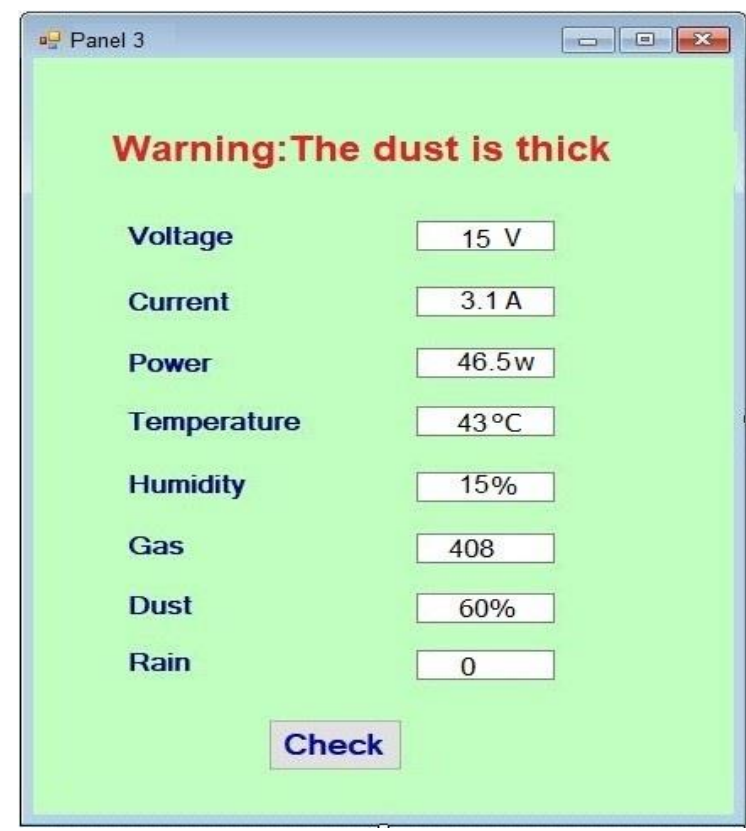

Fig. 7 Status page for panel 3

Panel 17

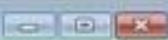

\section{Warning: Fume's Detected}

\begin{tabular}{l|c|} 
Voltage & $20 \mathrm{~V}$ \\
Current & $23 \mathrm{~A}$ \\
Power & $45 \mathrm{~W}$ \\
Temperature & $40{ }^{\circ} \mathrm{C}$ \\
Humidity & $15.7 \%$ \\
Gas & 700 \\
Dust & $27 \%$ \\
\hline Rain & 0 \\
\hline
\end{tabular}

Check

\section{THE RFID SYSTEM DESIGN}

The principle of RFID system functioning is an important part since it will improve the proposed monitoring system as it will facilitate the maintenance of solar panels quickly and easily. For example, when a fault occurs in a particular solar panel, it will require going to this solar panel to inspect and perform the necessary maintenance. However, before carrying out any such maintenance on this panel, one must be aware of its technical specifications and everything related to it in terms of the date of installation and all the previous sought maintenance and what faults it suffered previously so that the person who is responsible for the maintenance will be aware of all such details. Maybe this panel was previously exposed to the same fault several times and there is no point in going to get it back to service because it is going to be exposed to the same fault later. In such a case replacing this panel might be better than maintaining it. Figure 9 shows the proposed RFID device reader.

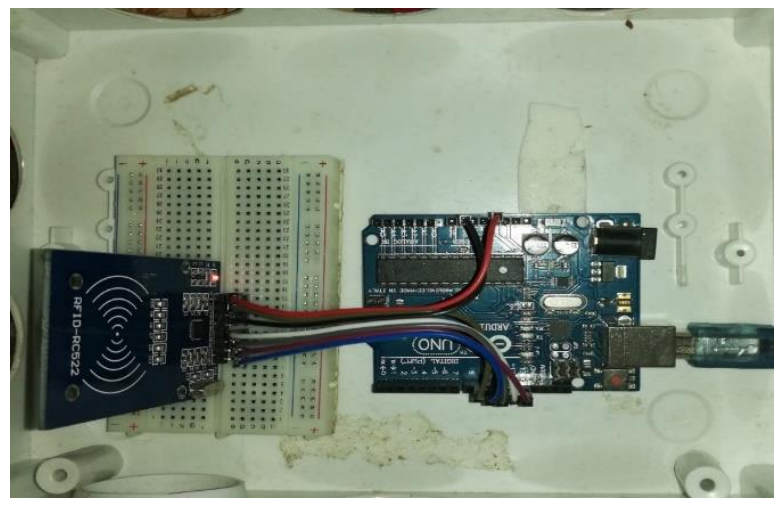

Fig. 9 The RFID device reader

\section{PRACTICAL IMPLEMENTATION}

The proposed system consists of a transmitter and receiver, which constitutes hardware components and a software part to program these hardware components. The data collected from sensors will be sent to the local server by NRF24 to detect faults in the station. Of course, in order to design a complete fault detection system to cover the solar station, many such hardware components are needed for all panels. There are various types of components that can be used in the detection system, but the cost should be considered. In this work, the used components are simple and of low cost and available in the local market. In addition, it gives high flexibility to the proposed system. The 
practical part of monitoring and detecting faults in solar panels has been successfully implemented on the solar power station installed in Baquba Technical Institute of the Central Technical University as shown in Figure 10.

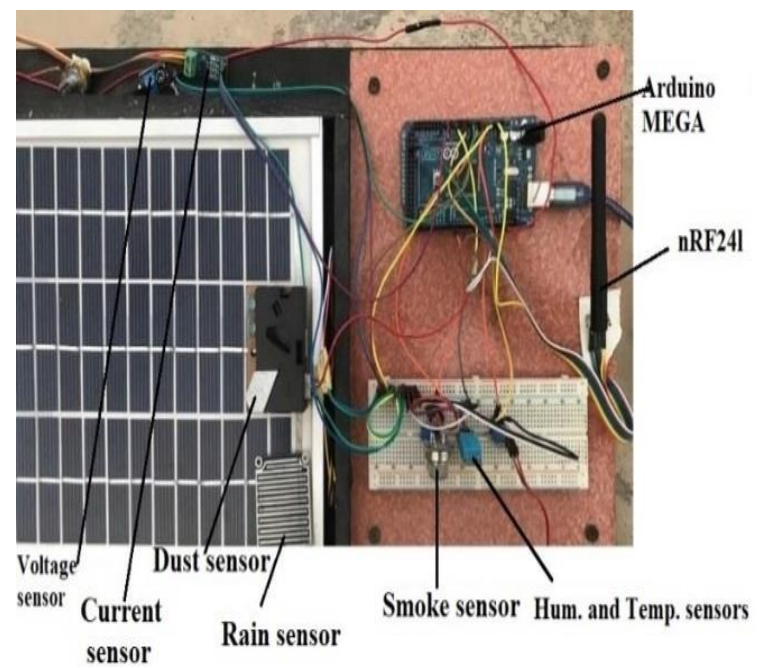

(a)

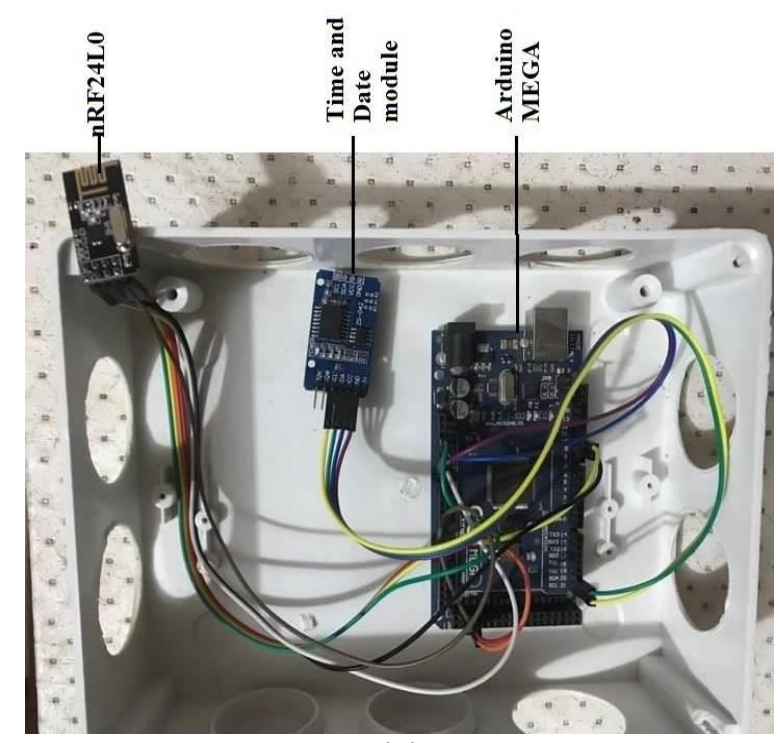

(b)

Fig. 10 Practical circuit connection

(a) Transmitter side, (b) Receiver side

\section{RESULTS AND DISCUSSION}

Figure 11 shows the recorded data of panel 1 in string 1. Each column represents a factor, which affects the solar panel efficiency at different times of the day. For example, in 7/8/2019 at $12.30 \mathrm{pm}$ the voltage is $23.2 \mathrm{~V}$, the current of this panel is $7.62 \mathrm{~A}$, and the corresponding power production is $176.78 \mathrm{~W}$. This high power production is due to many factors, one of these factors is the high solar irradiation at this time which is $800 \mathrm{~W} / \mathrm{m}^{\wedge} 2$, in addition to the high temperature which is $45{ }^{\circ} \mathrm{C}$. This shows that solar irradiation has positive effects on solar panel power production while the temperature has a negative effect. If the irradiation increases it leads to an increase in solar panel power production, but increasing irradiation also leads to an increase in the temperature, which, leads to a decrease in solar panel power production. The displayed smoke value is 432 at this time. This value is low in comparison with the maximum allowed value, as the allowed smoke range is between $(300-1000)$ ppm. This means no indication of fire or damage in the panels or wires. In addition, the recorded dust value is $31 \%$, and as is known, the dust reduces the sunlight falling on the solar panel which leads to a reduction in the energy generated by the solar panel and hence a reduction in the efficiency of the solar panel.

\section{P1 Date 7/8/2019}

\begin{tabular}{|c|c|c|c|c|c|c|c|c|c|}
\hline \multicolumn{10}{|c|}{ 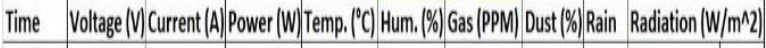 } \\
\hline 10.00 AM 18.36 & 5.7 & 104.652 & 43 & 16 & 431 & 25 & dry & 641 & \\
\hline 10.30 AM 18.43 & 6.33 & 116.6619 & 43 & 16 & 433 & 23 & $d r y$ & 673 & \\
\hline 11.00 AM 19.96 & 6.33 & 126.3468 & 43 & 16 & 436 & 24 & dry & 680 & \\
\hline $11.30 \mathrm{AM} 20$ & 7.22 & 144.4 & 44 & 16 & 430 & 28 & dry & 700 & \\
\hline 12.00 PM21.8 & 7.06 & 153.908 & 44 & 16 & 427 & 30 & $d r y$ & 760 & \\
\hline 12.30 PM 23.2. & 7.62 & 176,784 & 45 & 16 & 432 & 31 & $d r y$ & 800 & \\
\hline 01.00 PM21.9 & 7.1 & 155.49 & 45 & 16 & 438 & 33 & $d r y$ & 777 & \\
\hline 01,30 PM 22.28 & 7.25 & 161.53 & 45 & 16 & 430 & 30 & $d r y$ & 787 & \\
\hline 02.00 PM 21.54 & 6.96 & 149.9184 & 45 & 15 & 429 & 25 & $d r y$ & 753 & \\
\hline 02.30 PM 21.51 & 6.96 & 149.7096 & 45 & 16 & 431 & 25 & $d r y$ & 727 & \\
\hline
\end{tabular}

Fig. 11 Panel 1- String 1 recorded data

To validate the system performance, a uniformly distributed layer of dust was sprinkled on panel 6 in string 6 . The recorded data on this panel in 20/8/2019 at $12.00 \mathrm{pm}$ were as follows: the current is $5 \mathrm{~A}$, voltage is $13 \mathrm{~V}$, and the power production of this panel is only $65 \mathrm{~W}$. This power production is low according to the specification of this panel, which is $250 \mathrm{~W}$, as maximum power production. On checking this panel with the fault detector software, it indicates that the dust value is $70 \%$ which is very high. This dust stops a large amount of sunlight from falling on the solar panel, which leads to a reduction in the solar irradiation and the power production of this panel as shown in Figure 12. 


\section{P6 Date 20/8/2019}

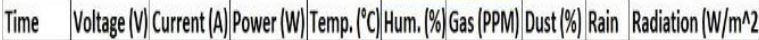

\begin{tabular}{|c|c|c|c|c|c|c|c|c|}
\hline 10.00 AM 23.2 & 7.62 & 176.784 & 31 & 16 & 431 & 25 & $d y$ & 450 \\
\hline 10.30 AM 23.8 & 7.86 & 187.068 & 31 & 16.1 & 433 & 23 & $d y$ & 500 \\
\hline 11.00 AM 24.6 & 7 & 172.2 & 32 & 16.7 & 436 & 24 & $d y$ & 560 \\
\hline 11.30 AM 24.2 & 6.18 & 149.556 & 32 & 16.6 & 430 & 28 & $d y$ & 580 \\
\hline 12.00 PM 13 & 5 & 65 & 32 & 16.5 & 427 & 70 & $d y$ & 300 \\
\hline 12,30 PM 25.2 & 6.25 & 157.5 & 43 & 16.6 & 432 & 31 & $d y$ & 620 \\
\hline $01.00 \mathrm{PM} / 25$ & 6.09 & 152.25 & 43 & 16.7 & 438 & 33 & $d r y$ & 610 \\
\hline $01.30 \mathrm{PM} 24.6$ & 5.9 & 145.14 & 42 & 16.5 & 430 & 3 & $d y$ & 600 \\
\hline $02.00 \mathrm{PM} 24.5$ & 7.62 & 186.69 & 42 & 15.7 & 429 & 25 & $d r y$ & 590 \\
\hline 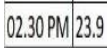 & 6.41 & 153.199 & 37 & 16 & 431 & 25 & dry & 390 \\
\hline
\end{tabular}

Fig. 12 Panel 6- String 6 recorded data

On discovering this fault in panel 6 , the operator in charge moves out to inspect this panel and test it on the spot using the designed RFID device to display the details of this panel including its previous maintenance history to discover the occurrence of damage in the panel connecting wires in a previous date in 2/4/2019 as shown in Figure 13. Figure 14 shows the typical recorded data on four other panels in the station.

This code scan the MIFARE Classsic NOID.

Using the following key: FF FF FF FF FF FFPICC type: MIFARE IKB A new card has been detected.

1337416067

Card Number: 1337416067

Panel ID: 6

Model Type: FRS-250 W

Peak Power (Pmax) : 250W

Peak Voltage (Vmp) : $30.50 \mathrm{~V}$

Peak Current (Imp) : $8.20 \mathrm{~A}$

Last Maintenance : 2/4/2019

Fault TYpe: Damaged Wires

Fig. 13 Panel 6 detail with RFID device

\section{P2 Date $11 / 8 / 2019$}

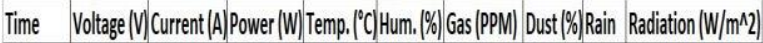

\begin{tabular}{|l|l|l|l|l|l|l|l|l|}
\hline 10.00 AM 20.1 & 7.09 & 142.509 & 41 & 15 & 423 & 23 & dry & 700 \\
\hline 10.30 AM 20.4 & 7.05 & 143.82 & 41 & 15.7 & 425 & 28 & dry & 710 \\
\hline 11.00 AM 20.6 & 6.29 & 129.574 & 41 & 15.7 & 428 & 27 & dry & 790 \\
\hline 11.30 AM 21.1 & 7 & 147.7 & 42 & 15.4 & 422 & 29 & dry & 840 \\
\hline 12.00 PM 21.72 & 6.66 & 144.6552 & 42 & 16 & 427 & 3 & dry & 900 \\
\hline 12.30 PM 23.94 & 7.91 & 189.3554 & 43 & 16.3 & 428 & 31 & dry & 987 \\
\hline 01.00 PM 23.84 & 7.82 & 186.4288 & 43 & 16.3 & 430 & 33 & dry & 970 \\
\hline 01.30 PM 23.7 & 7.88 & 186.756 & 44 & 15.8 & 430 & 3 & dry & 900 \\
\hline 02.00 PM 22.8 & 7.1 & 161.88 & 44 & 16 & 429 & 36 & dry & 860 \\
\hline 02.30 PM 21.6 & 7.2 & 155.52 & 44 & 16.5 & 431 & 37 & dry & 800 \\
\hline
\end{tabular}

(14. a)

\section{P3 Date $13 / 8 / 2019$}

Time Voltage (V) Current(A))Power(W) Temp. $\left.{ }^{\circ} \mathrm{C}\right)$ Hum. $(\%)$ Gas (PPM) Dust(\%) Rain Radiation(W/ $/ \mathrm{m}^{\wedge} 2$

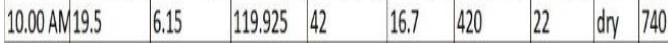
\begin{tabular}{l|l|l|l|l|l|l|l|l}
\hline 10.30 AN24 & 6.93 & 166.32 & 42 & 16.4 & 423 & 23 & dry & 730 \\
\hline
\end{tabular} \begin{tabular}{|l|l|l|l|l|l|l|l|l|}
\hline 11.00 AN23.8 & 7.86 & 187.068 & 43 & 16.2 & 415 & 24 & dry & 750 \\
\hline
\end{tabular} \begin{tabular}{l|l|l|l|l|l|l|l|l}
\hline 11.30 AN23 & 7.54 & 173.42 & 43 & 15.4 & 426 & 29 & dry & 700
\end{tabular}

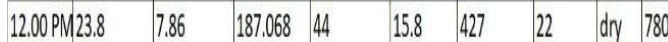
\begin{tabular}{|l|l|l|l|l|l|l|l|l|}
\hline 12.30 PM 21.7 & 7.02 & 152.334 & 44 & 16.2 & 423 & 27 & dry & 800 \\
\hline
\end{tabular} \begin{tabular}{|l|l|l|l|l|l|l|l|l|}
\hline 01.00 PM19.9 & 6.9 & 137.31 & 45 & 15.4 & 428 & 27 & dry & 790
\end{tabular} \begin{tabular}{l|l|l|l|l|l|l|l|l}
\hline 01.30 PM21.2 & 6.41 & 135.892 & 45 & 15.4 & 430 & 30 & dry & 750
\end{tabular} \begin{tabular}{l|l|l|l|l|l|l|l|l}
\hline 02.00 PM25.1 & 6.37 & 159.887 & 45 & 16.5 & 429 & 31 & dry & 740
\end{tabular} \begin{tabular}{|l|l|l|l|l|l|l|l|l|}
\hline 02.30 PM 25.2 & 6.41 & 161.532 & 45 & 16.6 & 431 & 25 & dry & 700 \\
\hline
\end{tabular}

(14. b)

\section{P4 Date 155/2019}

\begin{tabular}{|c|c|c|c|c|c|c|c|c|}
\hline Time Volta & 1) Curre & ||Power (V & ITT & I & 3) Gas & & i) Rain & \\
\hline 10.00 AN 19 & 6.41 & 121.79 & 40 & 14.4 & 400 & 17 & $d y$ & 500 \\
\hline 10.30AN19.2 & 6.41 & 123.072 & 40 & 14.4 & 413 & 20 & $d y$ & 560 \\
\hline 11.00AN19.4 & 6.37 & 123.578 & 40 & 14.2 & 412 & 24 & $d r$ & 540 \\
\hline 11.30 AN20 & 7.14 & 142.8 & 41 & 14 & 415 & 26 & $d y$ & 600 \\
\hline 12.00 PM20.1 & 7.62 & 153.162 & 41 & 14 & 419 & 22 & $d y$ & 610 \\
\hline 12,30 PM20 & 6.25 & 125 & 41 & 14.8 & 423 & 27 & $d y$ & 615 \\
\hline 01.00 PM20.1 & 8.05 & 161.805 & 41 & 15 & 411 & 23 & $d y$ & 600 \\
\hline 01.30 PM19.6 & 7.45 & 146.02 & 41 & 14.8 & 432 & 28 & $d y$ & 594 \\
\hline 02.00 PM19.1 & 7.93 & 151.463 & 42 & 15.7 & 415 & 30 & $d y$ & 591 \\
\hline 02.30 PM19 & 6.49 & 123.31 & 42 & 16 & 409 & 25 & $d y$ & 530 \\
\hline
\end{tabular}

(14.c)

\section{P5 Date 18/82019}

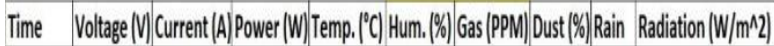

\begin{tabular}{|c|c|c|c|c|c|c|c|}
\hline $10.00 \mathrm{AM} / 20$ & 6.45 & 129 & 38 & 14 & 407 & 15 & dry 600 \\
\hline $10.30 \mathrm{AM} 20$ & 6.41 & 128.2 & 38 & 14 & 415 & 20 & dry 605 \\
\hline 11.00AM 21 & 7,3 & 153.3 & 43 & 15.7 & 412 & 22 & dry 610 \\
\hline 11.30AM 21.3 & 5.51 & 117,363 & 40 & 15 & 416 & 21 & din 700 \\
\hline 12.00PM 21.3 & 6.86 & 146.118 & 43 & 15.4 & 419 & 22 & dry 650 \\
\hline $12.30 \mathrm{PM} 25$ & 6.49 & 162.25 & 40 & 15 & 420 & 21 & dry 690 \\
\hline $01.00 \mathrm{PM} / 25$ & 6.41 & 160.25 & 41 & 15.6 & 409 & 23 & dry 640 \\
\hline $01.30 \mathrm{PM} 20.9$ & 7.3 & 152.57 & 30 & 13.6 & 410 & 23 & dry 620 \\
\hline $02.00 \mathrm{PM} 17.5$ & 5.36 & 93.8 & 43 & 15.7 & 416 & 20 & dry 600 \\
\hline 02.30 PM 21.3 & 6.86 & 146.118 & 43 & 16 & 430 & 21 & dry 610 \\
\hline
\end{tabular}

$$
\text { (14.d) }
$$

Fig. 14 Recorded data,
(a) Panel 2- String 2,
(b) Panel 3- String 3,
(c) Panel 4- String 4,
(d) Panel 5- String 5 


\section{CONCLUSIONS}

In this paper, a hybrid PV panel monitoring system has been designed based on two communication technologies; namely WSN and RFID. The WSN part consists of multi-sensors (voltage, current, temperature, humidity, dust, smoke, radiation, and rain) that are installed on each PV panel. These sensors can collect data from $P V$ panels and send them via Wi-Fi modules to the cloud database where a user can log in and monitor the PV system in real-time. The RFID part has been added to this system to give more flexibility to the monitoring system if there is no internet connection by sending the recorded data to a local receiver. A panel information detector has been added to this monitoring system to facilitate the detection of the history information of all panels. In addition, fault type detector software is designed based on C\# programming language and MySQL database to detect the types of faults that affect the PV panels. The proposed monitoring system has been successfully implemented to an existing solar station installed in the Technical Institute/Baquba, Iraq.

\section{WORKS CITED}

Al-Naima, F., \& Hamad, A. (2019). A Low-cost Solar Farm Monitoring System Based on Cloud Database. MEST Journal Vol. 7 No. 2 pp.1-8, July 2019.

Bashir, A. K., Lim, S. J., Hussain, C. S., \& Park, M. S. (2011). Energy efficient in-network RFID data filtering scheme in wireless sensor networks. Sensors, 11(7), 7004-7021. https://doi.org/10.3390/s110707004

Bilic, H. G., Buyukoztekin, T., \& Ozdemir, S. (2019). The Use of Chipless Sensors with RFID for Condition Monitoring. 2018 International Conference on Artificial Intelligence and Data Processing, IDAP 2018, (February 2019), 1-4. https://doi.org/10.1109/IDAP.2018.8620810

Ferrara, C., \& Philipp, D. (2012). Why do PV modules fail? Energy Procedia, Vol. 15, pp. $379-387$. https://doi.org/10.1016/j.egypro.2012.02.046

Guerriero, P., Vallone, G., Primato, M., Di Napoli, F., Di Nardo, L., D’Alessandro, V., \& Daliento, S. (2014). A wireless sensor network for the monitoring of large PV plants. 2014 International Symposium on Power Electronics, Electrical Drives, Automation and Motion, SPEEDAM 2014, (November), 960-965. https://doi.org/10.1109/SPEEDAM.2014.6872084

Jaiswal, A. W. N. S. K. (2015). Anti-Collision in WSN and RFID Network Integration. International Journal of Science and Research (IJSR), 4(4), 3008-3012. Retrieved from https://www.ijsr.net/archive/v4i4/SUB153860.pdf

Wahyuni, R. T., \& Wijaya, Y. P. (2017). Solar panel performance monitoring system in sensor node. 2016 International Symposium on Electronics and Smart Devices, ISESD 2016, 92-96. https://doi.org/10.1109/ISESD.2016.7886699

Received for publication: $\quad 16.12 .2019$

Revision received: $\quad 23.12 .2019$

Accepted for publication: $\quad 10.01 .2020$

\section{How to cite this article?}

Style - APA Sixth Edition:

Al-Naima, F. M., \& Wahab, M. M. (2020, January 15). A hybrid design procedure for fault diagnosis in a PV power plant. (Z. Cekerevac, Ed.) MEST Journal, 8(1), 7-14. doi:10.12709/mest.08.08.01.02

Style - Chicago Sixteenth Edition:

Al-Naima, Fawzi M., and Maysam M. Wahab. 2020. "A hybrid design procedure for fault diagnosis in a PV power plant." Edited by Zoran Cekerevac. MEST Journal (MESTE) 8 (1): 7-14. doi:10.12709/mest.08.08.01.02. 
Style - GOST Name Sort:

Al-Naima Fawzi M. and Wahab Maysam M. A hybrid design procedure for fault diagnosis in a PV power plant [Journal] // MEST Journal / ed. Cekerevac Zoran. - Belgrade - Toronto : MESTE, January 15, 2020. - 1 : Vol. 8. - pp. 7-14.

Style - Harvard Anglia:

Al-Naima, F. M. \& Wahab, M. M., 2020. A hybrid design procedure for fault diagnosis in a PV power plant. MEST Journal, 15 January, 8(1), pp. 7-14.

Style - ISO 690 Numerical Reference:

A hybrid design procedure for fault diagnosis in a PV power plant. Al-Naima, Fawzi M. and Wahab, Maysam M. [ed.] Zoran Cekerevac. 1, Belgrade - Toronto : MESTE, January 15, 2020, MEST Journal, Vol. 8, pp. 7-14. 